\title{
Influence of breathing pattern on lung deposition and bronchodilator response to nebulised salbutamol in patients with stable asthma
}

\author{
B M Z ZAINUDIN, S E J TOLFREE, M SHORT, STEPHEN G SPIRO \\ From the Departments of Respiratory Medicine and Medical Physics, University College Hospital, London
}

ABSTRACT The influence of breathing pattern on lung deposition and bronchodilator response to nebulised salbutamol is uncertain. Three different breathing patterns were assessed in eight patients with chronic stable asthma. Salbutamol solution $(2.5 \mathrm{mg}$ in $4 \mathrm{ml})$ mixed with technetium-99m labelled human serum albumin was nebulised by an Acorn nebuliser at a flow rate of 6 litres a minute. Particles with a mass median aerodynamic diameter of $4.8 \mu \mathrm{m}$ were produced for inhalation by $(a)$ tidal breathing, $(b)$ six tidal breaths followed by three deep breaths, and $(c)$ six tidal breaths followed by three deep breaths with a five second breath hold after each breath. Each breathing pattern was continued for four minutes. There was no significant difference in the percentage of radioaerosol deposited in the lung or in the distribution of radioaerosol within the lung as assessed by gamma camera imaging. Changes in bronchodilator responses as measured by peak expiratory flow rate (PEF), forced expiratory volume in one second $\left(\mathrm{FEV}_{1}\right)$, and forced vital capacity (FVC) 30, 45, and 60 minutes after inhalation were similar for the three studies. The mean (SEM) maximum percentage change in $\mathrm{FEV}_{\text {, was }} 44(7 \cdot 1), 47(9 \cdot 2)$, and $51(8 \cdot 4)$ for studies 1,2 , and 3 respectively. The percentage of nebulised solution deposited in the body was also similar for the three breathing patterns - that is, $11-13 \%$, of which $98 \%$ entered the lung. This study shows that inhaling a nebulised aerosol by tidal breathing, the simplest method, is as effective as tidal breathing with deep breaths with or without a breath hold.

\section{Introduction}

Aerosol inhalation is regarded as the most efficient way to administer bronchodilator drugs to asthmatic patients, ${ }^{1-4}$ causing a rapid onset of action with minimal side effects. Its efficacy depends on the quantity of drug delivered to the lung and perhaps to the pattern of distribution in the lung. In addition to particle size, which has been shown to be important in determining the dose of aerosol deposited in the lung, ${ }^{5}$ and its effect on lung function, ${ }^{6}$ the breathing pattern may be important. Increasing the volume of a breath, for example, has the potential of depositing more aerosol in the lung. Newhouse and Ruffin ${ }^{7}$ showed that just two slow vital capacity breaths deposited more than half of the total nebulised aerosol dose deposited in the lung during two minutes of tidal breathing. Greater penetration of nebulised aerosol into periAddress for reprint requests: Dr S G Spiro, Brompton Hospital,
London SW3 6HP.

Accepted 26 September 1988 pheral airways has been shown to occur when small particles are inhaled by slow vital capacity breathing. ${ }^{8}$ Breath holding may also, however, be important, particularly at the end of inhalation, as it may allow a longer residence time for the particles to settle by gravitational sedimentation within the peripheral airways. Newman et $a l^{9}$ showed that greater aerosol deposition in the lung was achieved during inhalation from a pressurised aerosol with a 10 second breath hold after each puff.

These studies prompted us to investigate any effect that different breathing patterns may have on the lung deposition and bronchodilator response produced by a nebulised bronchodilator. The study design attempted to minimise difficulties that might be encountered by patients performing breathing manoeuvres so that the methods could be readily applied in clinical practice.

\section{Methods}

PATIENTS

Eight patients (four men and four women), mean age 
59 (SD 8) years), with asthma were studied while clinically stable. All took regular inhaled bronchodilators and corticosteroids and five were also taking oral theophylline. Their baseline forced expiratory volume in one second $\left(\mathrm{FEV}_{1}\right)$ ranged from $36 \%$ to $79 \%$ (mean $52 \%$ (SD 6.3\%)) of predicted values ${ }^{10}$ and improved by at least $20 \% 15$ minutes after the inhalation of $200 \mu \mathrm{g}$ salbutamol administered by metered dose inhaler. All oral and inhaled bronchodilator medication was withdrawn for 18 and 12 hours respectively prior to each study day. The patients were allowed to have breakfast, including decaffeinated tea or coffee, on the morning of a study day. The studies were performed on three separate days, a week apart (excluding the assessment day). The $\mathrm{FEV}_{1}$ had to be within $15 \%$ of the initial baseline value on each subsequent study day; if it was not, another appointment was arranged. Informed written consent was obtained from the patients and the study was approved by the ethical committee of University College and the Middlesex Hospital School of Medicine.

\section{STUDY DESIGN}

On the assessment day the following three different breathing manoeuvres were explained and taught to patients who met the criteria for the study. Study 1 Tidal breathing: patients were instructed to breathe in their usual resting manner through their mouths. Study 2 Tidal breathing for six breaths alternating with three slow deep breaths: that is, deep inhalation from functional residual capacity (slow inspiratory capacity). Study 3 Tidal breathing for six breaths alternating with three slow deep breaths with a five second breath hold at the end of each deep breath.

Each breathing pattern was performed for four minutes at the patient's chosen respiratory rate and inspiratory volume. One investigator counted the number of breaths while the patients performed studies 2 and 3 and instructed them to breathe in deeply from functional residual capacity and hold their breath at the appropriate time. Inspiratory volume and respiratory rate were recorded.

On each study day baseline measurements of peak expiratory flow rate (PEF), $\mathrm{FEV}_{1}$, and forced vital capacity (FVC) were carried out 30 and 15 minutes before the study. The best of three readings was selected and recorded. Each patient then inhaled nebulised aerosol by each of the three breathing patterns in random order on separate occasions. PEF, $\mathrm{FEV}_{1}$, and FVC measurements were repeated 30, 45, and 60 minutes after inhalation of the aerosol.

RADIOAEROSOL PREPARATION

Technetium-99m labelled human serum albumin, 200 $\mathrm{MBq}$, was mixed with $2.5 \mathrm{mg}$ salbutamol and an appropriate volume of normal saline to make a total of
$4 \mathrm{ml}$. The solution was nebulised by an Acorn je? nebuliser (Medic-aid) driven with compressed air at flow rate of 6 litres a minute. The particles generate had a mass median aerodynamic diameter (MMADP of 4.8 (SD 2.4) $\mu \mathrm{m}$ as measured by a multistage cascadê impactor (290 Marple personal Cascade Impactor $\vec{\circ}$ Andersen Samplers Inc). Sixty per cent of the aerosol mass was contained in particles with diameters less. than $6 \mu \mathrm{m}$.

RADIONUCLIDE IMAGING TECHNIQUE

The nebuliser and its connecting tubes were placed in $\frac{\vec{d}}{d}$ lead box. Each patient inhaled the aerosol via $\vec{a}$ mouthpiece with the nostrils occluded by a nose clip. $\$_{00}^{\circ}$ three way valve directed the flow of inspired gas from the nebuliser to the patient and the expired gas to anp expiratory tube and filter, so that there was no mixing of inspired and expired gas. This allowed an accurate measurement of the expired radioactivity. The in spired gas passed through a Fleisch pneumo tachograph (No 4) connected to a flow integrato? (Gould-Godart) and a chart recorder for measure $\vec{\imath}$ ment of the inspired gas volume and respiratory rate Immediately after inhaling the aerosol patients were imaged seated in front of a dual headed gammo camera (Siemens Rota camera), which acquired simul taneous anterior and posterior views. Images of lung@ throat, and stomach were collected to a count limit of $400 \mathrm{~K}$ for the lung view and a time limit of 120 seconds. for the throat and stomach views. The gamma camer was interfaced to an ADAC computer and the data were stored on magnetic tape for subsequent analysis Counts in regions of interest delineating the lung. throat, and stomach were obtained and geometrie mean values calculated. The values were corrected fo background radioactivity and the attenuation of photons in the chest wall, neck, and abdomen. These were expressed as percentages of the initial activitis present in the nebuliser solution after correction foB radioactive decay. The distribution of radioactivity it the lung was also assessed by dividing the lung into peripheral third and a central two thirds; counts in the peripheral area were expressed as percentages of totar lung deposition. The mass of salbutamol deposited a\$ various sites in the body was determined from the percentage deposition in each area. The radioactivitw in the inspiratory tube, Fleisch pneumotachographmouthpiece and three way valve was counted together but separately from that of the expiratory tube an

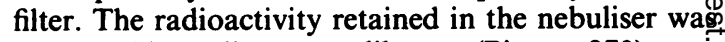
measured by radioassay calibrator (Pitman 270).

The maximum radiation dose absorbed by eace subject as a result of the three administrations was $\vec{\phi}$ $\mathrm{mGy}$ for the lungs and $0.3 \mathrm{mGy}$ for the whole body. $\frac{\mathbb{D}}{\mathbb{D}}$

STATISTICAL ANALYSIS

An analysis of variance was used to identify differences 
Table 1 Mean (SEM) baseline values for peak flow $(P E F), F E V_{1}$, and forced vital capacity $(F V C)$ and the maximum percentage change after inhalation of nebulised salbutamol in the three studies*

\begin{tabular}{lccc}
\hline Lung function & Study I & Study 2 & Study 3 \\
\hline Baseline PEF (1/min) & $262(22)$ & $252(19)$ & $264(19)$ \\
Baseline FEV $_{1}(1)$ & $1 \cdot 31(0 \cdot 10)$ & $1 \cdot 33(0 \cdot 10)$ & $1 \cdot 30(0 \cdot 07)$ \\
Baseline FVC (1) $_{\text {Maximum \% change in: }}$ & $2 \cdot 41(0 \cdot 18)$ & $2 \cdot 39(0 \cdot 16)$ & $2 \cdot 46(0 \cdot 16)$ \\
PEF & $34 \cdot 8(8 \cdot 6)$ & $42 \cdot 3(10 \cdot 3)$ & $38 \cdot 3(8 \cdot 6)$ \\
FEV & $44 \cdot 3(7 \cdot 1)$ & $47 \cdot 4(9 \cdot 2)$ & $51 \cdot 1(8 \cdot 4)$ \\
FVC & $37 \cdot 1(5 \cdot 7)$ & $39 \cdot 9(6 \cdot 9)$ & $37 \cdot 9(6 \cdot 0)$ \\
\hline
\end{tabular}

*Study 1: tidal breathing; study 2: six tidal breaths followed by three deep breaths; study 3 : six tidal breaths followed by three deep breaths each followed by a five second breath hold.

Table 2 Mean (SEM) values of respiratory rate, ventilation, and lung deposition of radioaerosol and salbutamol

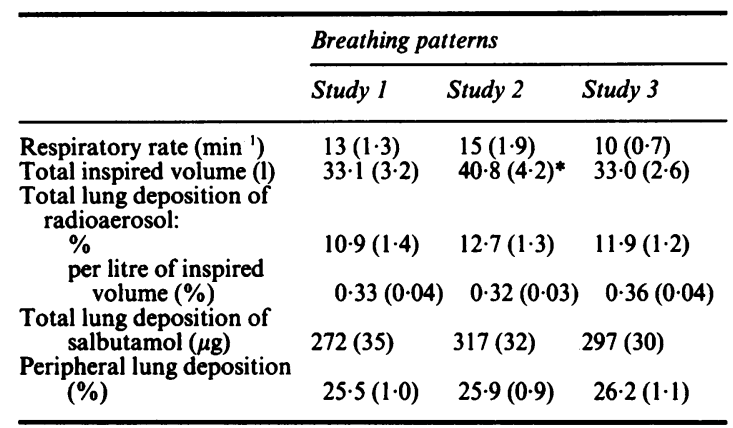

*p < 0.01: study $2 v$ studies 1 and 3 .

in mean values for the three treatment groups and the paired Student's $t$ test for multiple comparisons. ${ }^{11}$ A p value of $<0.05$ was considered significant.
Table 3 Mean (SEM) percentages of aerosol deposited in the lung and stomach and in the apparatus

\begin{tabular}{|c|c|c|c|}
\hline & \multicolumn{3}{|c|}{ Breathing patterns } \\
\hline & Study 1 & Study 2 & Study 3 \\
\hline $\begin{array}{l}\text { Lungs } \\
\text { Gastrointestinal tract* } \\
\text { Expiratory tube and filter } \\
\text { Nebuliser and inspiratory } \\
\text { tube }\end{array}$ & $\begin{array}{c}10 \cdot 9(1 \cdot 4) \\
0 \cdot 23(0 \cdot 07) \\
4 \cdot 0(0 \cdot 8) \\
84.9(2 \cdot 0)\end{array}$ & $\begin{array}{l}12 \cdot 7(1 \cdot 3) \\
0 \cdot 34(0 \cdot 07) \\
5 \cdot 8(0 \cdot 6) \\
81 \cdot 3(1 \cdot 6)\end{array}$ & $\begin{array}{l}11 \cdot 9(1 \cdot 2) \\
0 \cdot 24(0 \cdot 06) \\
4 \cdot 1(0 \cdot 4) \\
83 \cdot 7(1 \cdot 3)\end{array}$ \\
\hline
\end{tabular}

\section{Results}

There was no difference in baseline values of PEF, FEV , and FVC for the three studies. All patients showed a considerable bronchodilator response (table 1). Total ventilation during the four minutes was significantly greater in study $2(40.81)$ than in either study $1(33.11)$ or study $3(33.01)$ (table 2$)$. There was a trend towards a greater lung deposition of radioaerosol in study 2 but the differences between the three studies were not statistically significant, and when lung deposition was corrected for volume inspired the values for percentage deposition were in fact very similar (table 2 ). The three breathing manoeuvres also resulted in similar patterns of aerosol distribution within the lung.

The mean (SEM) percentage improvement for PEF, $\mathrm{FEV}_{1}$, and FVC 30, 45, and 60 minutes after inhalation of aerosol are summarised in the figure. There was no significant difference between the three groups in the improvement in lung function at any time of measurement.

The distribution of aerosol deposited within the
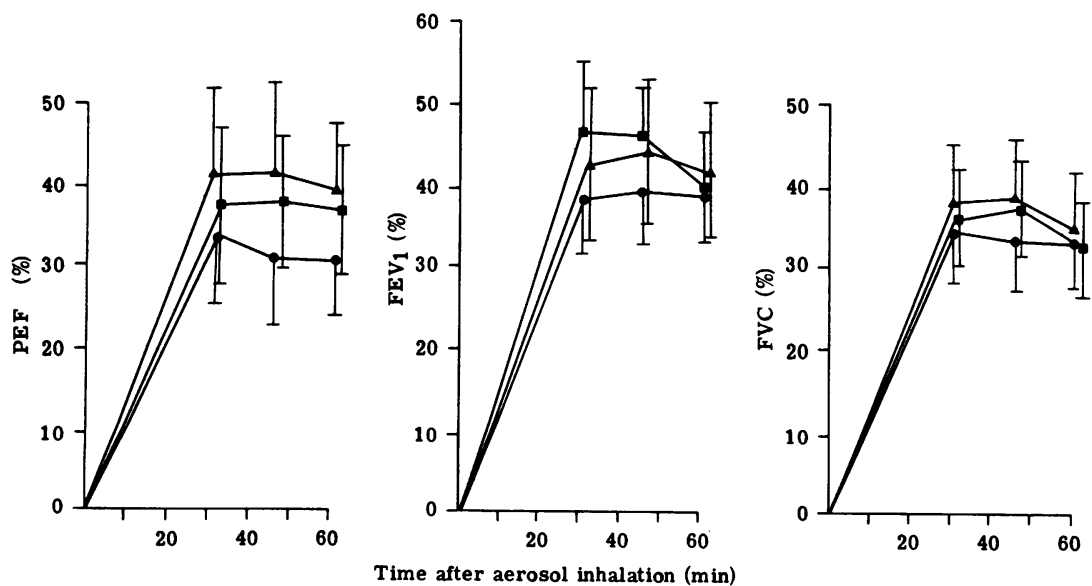

Changes in peak expiratory flow (PEF), FEV , and forced vital capacity (FVC) 30, 45, and 60 minutes after inhalation of salbutamol with each breathing pattern. Study 1 (tidal breathing); $\Delta$ study 2 (six tidal breaths followed by three deep breaths); $\mathbf{s t u d y} 3$ (six tidal breaths followed by three deep breaths followed by a five second breath hold). 
body and apparatus was similar during the three breathing studies (table 3).

\section{Discussion}

Nebulisers are often used in the treatment of acute asthma, where a stable or predetermined breathing pattern is difficult to achieve, but in addition their use has increased in the treatment of less severe airways obstruction and also for aerosol treatment of lung infections, such as Pseudomonas aeruginosa infection in patients with cystic fibrosis ${ }^{12}$ and Pneumocystis carinii infection in patients with human immunodeficiency virus. ${ }^{13}$ In these conditions a controlled breathing pattern may be desirable.

The effects of various breathing patterns have been well studied with the pressurised aerosol inhaler, but studies of nebulised aerosol are scanty. Our study shows that for the three breathing patterns chosen the same quantity of bronchodilator aerosol is deposited within the lungs, with a similar pattern of distribution. The higher ventilation in study 2 did not cause a significantly greater deposition of aerosol in the lung. This may be because higher inspiratory flow rates were attained during deep breathing (inspiratory capacity breathing) in studies 2 and 3. Although patients were instructed to inhale slowly during all three breathing periods, the flow rates during the performance of deep breathing varied considerably between deep breaths by the same patients and were generally higher than when they were breathing at tidal volume. We calculated the inspiratory flow rate from the plot of inspired volume and respiratory rate, obtaining flow rates of 15-40 1/min during tidal breathing compared with 25$80 \mathrm{l} / \mathrm{min}$ with deep breaths. Less lung deposition of nebulised aerosol has been shown to result from higher flow rates for inspiration to total lung capacity than from lower flow rates. ${ }^{714}$ In both the studies concerned, however, the patients performed the breathing manoeuvres for only two breaths and were therefore able to control the inspiratory flow rate more easily.

Holding the breath at the end of a deep inhalation was difficult for the subjects to perform and failed to provide any advantage. No previous study has looked for this effect with nebulised particles, though Lawford and McKenzie, ${ }^{15}$ using a pressurised bronchodilator, also failed to show any significant difference in bronchodilator responses with 10 second and four second breath holding periods. Newman $e t$ $a l,{ }^{9}$ however, found some improvement in lung deposition of radiolabelled pressurised aerosol in a similarly designed study.

The amount of nebulised solution left in the apparatus after nebulisation is substantial, only $11-$ $13 \%$ being deposited within the body. Of this, however, more than $95 \%$ enters the lungs and only a small percentage is found in the throat and stomach당 Throat impaction is much greater with the metere dose inhaler ${ }^{16}$ because of the greater particle velocit generated by the pressurised canister system. Moreover, particles generated by a nebuliser are relatively constant and optimal in size for lung depos $\vec{b}$ tion from the moment they leave the generator whereas those produced by a metered dose inhaler are initially much larger and decrease in size only aftef travelling for some distance. ${ }^{18}$ Thus, although these slow moving, homogeneous particles seemed likely to be affected by breathing patterns, our study has showi none of the three techniques to be superior. The simplest pattern of all, tidal breathing, is effective and was easily performed by all patients.

We wish to express our appreciation to Miss Barbarg Webber, senior physiotherapist, Brompton Hospitaథ for her assistance in this study and to Miss Ange: Betchley for typing the manuscript with great care BMZZ was supported by the University Kebangsaan. Malaysia.

\section{References}

1 Davies DS. Pharmacokinetics of inhaled substances. Postgrad Med J 1975;51(suppl 7):69-75.

2 Webb J, Rees J, Clark TJH. A comparison of the effects of different methods of administration of $\beta_{2}$ sympath $\overline{\alpha_{4}^{2}}$ mimetics in patients with asthma. $B r J$ Dis Chest 1980; 76:351-7.

3 Newhouse MT, Dolovich M. Aerosol therapy reversible airflow obstruction. Concepts and clinical applications. Chest 1987;91(suppl):58-63S.

4 Brain JD, Valberg PA. Deposition of aerosol in the respiratory tract. Am Rev Respir Dis 1979;120:1325-

5 Clay MM, Clarke SW. Effect of nebulised aerosol size of lung deposition in patients with mild asthma. Thorax 1987;42:190-4.

6 Rees PJ, Clark TJH. The importance of particle size is response to inhaled bronchodilators. Eur J Respir 1982;63(suppl 119):73-8.

7 Newhouse MT, Ruffin RE. Deposition and fate $\widetilde{\mathscr{P P}}$ aerosolised drugs. Chest 1978;73:936-42.

8 Dolovich M, Ryan G, Newhouse MT. Aerosol penetra tion into lung. Chest 1981;80(suppl):834-6.

9 Newman SP, Pavia D, Garland N, Clarke SW. Effects of various inhalation modes on the deposition of radil active pressurised aerosols. Eur J Respir Dis 198ळ; 63(suppl 119):57-65.

10 Cotes JE. Lung function: assessment and application tit medicine. 3rd ed. Oxford: Blackwell, 1975:380-9.

11 Armitage P, Berry G. Statistical methods in medic, research. 2nd ed. Oxford: Blackwell, 1987:186-220. $\frac{1}{\mathbb{D}}$

12 Hodson ME, Penketh ARL, Batten JC. Aerosô carbenicillin and gentamicin treatment fof pseudomonas aeruginosa infection in patients wigh 
cystic fibrosis. Lancet $1981 ;$;i:1137-9.

13 Montgomery AB, Luce JM, Turner J, et al. Aerosolised pentamidine as sole therapy for Pneumocystis carinii pneumonia in patients with acquired immunodeficiency syndrome. Lancet 1987;ii:480-3.

14 Ryan G, Dolovich MB, Obminski G, Cockcroft DW, Hargreave FE, Newhouse MT. Standardization of inhalation provocation tests: Influence of nebuliser output, particle size and method of inhalation. $J$ Allergy Clin Immunol 1981;67:156-61.

15 Lawford P, McKenzie D. Pressurized bronchodilator aerosol technique: influence of breath-holding time and relationship of inhaler to the mouth. Br J Dis Chest 1982;76:229-33.

16 Newman SP, Pavia D, Moren F, Sheahan NF, Clarke SW. Deposition of pressurised aerosols in the human respiratory tract. Thorax 1981;36:52-5.

17 Clarke SW, Newman SP. Differences between pressurised aerosol and stable dust particles. Chest 1981;80:907-8.

18 Moren F, Andersson J. Fraction of dose exhaled after administration of pressurised inhalation aerosols. Int $J$ Pharmaceut 1980;6:295-300. 